\title{
Genome-resolved viral and cellular metagenomes revealed potential key virus-host interactions in a deep freshwater lake
}

\author{
Yusuke Okazaki ${ }^{a, b, 1}$, Yosuke Nishimura ${ }^{c, d, e}$, Takashi Yoshida $^{c}$, Hiroyuki Ogata $^{d}$, \\ Shin-ichi Nakano ${ }^{a}$
}

a. Center for Ecological Research, Kyoto University, 2-509-3 Hirano, Otsu, Shiga 520-2113, Japan

b. Bioproduction Research Institute, National Institute of Advanced Industrial Science and

Technology, Central 6, Higashi 1-1-1, Tsukuba, Ibaraki 305-8566, Japan.

c. Graduate School of Agriculture, Kyoto University, Kitashirakawa-Oiwake, Sakyo-ku, Kyoto 6068502, Japan

d. Institute for Chemical Research, Kyoto University, Uji, Kyoto 611-0011, Japan

e. Atmosphere and Ocean Research Institute, The University of Tokyo, Chiba 277-8564, Japan

${ }^{1}$ Corresponding author:

Yusuke Okazaki

Bioproduction Research Institute, National Institute of Advanced Industrial Science and Technology,

Central 6, Higashi 1-1-1, Tsukuba, Ibaraki 305-8566, Japan.

E-mail: okazaki.yusuke.e31@kyoto-u.jp

Phone: +81-29-861-6591, Fax: +81-29-861-6587

Running title: Metagenomic exploration of freshwater phages

Competing interests: The authors declare no conflicts of interest. 


\section{Summary}

Metagenomics has dramatically expanded the known virosphere, but freshwater viral diversity and their ecological interaction with hosts remain poorly understood. Here, we conducted a metagenomic exploration of planktonic dsDNA prokaryotic viruses by sequencing both virion $(<0.22 \mu \mathrm{m})$ and cellular $(0.22-5.0 \mu \mathrm{m})$ fractions collected spatiotemporally from a deep freshwater lake (Lake Biwa, Japan). This simultaneously reconstructed 183 complete (i.e., circular) viral genomes and 57 bacterioplankton metagenome-assembled genomes. Analysis of metagenomic read coverage revealed vertical partitioning of the viral community analogous to the vertically stratified bacterioplankton community. The hypolimnetic community was generally stable during stratification, but occasionally shifted abruptly, presumably due to lysogenic induction. Genes involved in assimilatory sulfate reduction were encoded in $20(10.9 \%)$ viral genomes, including those of dominant viruses, and may aid viral propagation in sulfur-limited freshwater systems. Hosts were predicted for 40 (21.9\%) viral genomes, encompassing 10 phyla (or classes of Proteobacteria) including ubiquitous freshwater bacterioplankton lineages (e.g., $\mathrm{Ca}$. Fonsibacter and $\mathrm{Ca}$. Nitrosoarchaeum). Comparison with viral genomes derived from published metagenomes revealed viral phylogeographic connectivity in geographically isolated habitats. Notably, analogous to their hosts, actinobacterial viruses were among the most diverse, ubiquitous, and abundant viral groups in freshwater systems, with potential high lytic activity in surface waters. 


\section{Introduction}

Since the discovery three decades ago that a large number of viruses are present in aquatic systems (Bergh et al., 1989), our understanding of viral ecology has grown in an unprecedented manner. Whereas viruses can infect cells of all three domains of life, those infecting bacteria and archaea have been studied extensively, as they are numerically dominant and play important roles in their ecosystems. Such viruses rewire the microbial food web by releasing the host's cellular contents back into the environment (the viral shunt) (Wilhelm and Suttle, 1999) and may carry host-derived metabolic genes (auxiliary metabolic genes; AMGs), which amend the host's metabolism to facilitate viral propagation (Breitbart et al., 2007). They are key players in maintaining the diversity of the microbial community by selectively killing the dominant hosts (Thingstad, 2000) or promoting the genetic diversification of hosts (Koskella and Brockhurst, 2014; Touchon et al., 2017).

Although freshwater ecosystems occupy a small portion of the earth's surface, these areas cycle petagrams of carbon per year globally (Tranvik et al., 2009; Raymond et al., 2013), and are of great importance to humans as drinking water sources. Furthermore, freshwater ecosystems are vulnerable to climate change (Posch et al., 2012; Woolway and Merchant, 2019) and eutrophication (Jenny et al., 2016). Microbial processes are key to understanding these ecological and biogeochemical mechanisms. Researchers have reached the consensus that surface freshwater systems (epilimnion) are ubiquitously dominated by bacterioplankton lineages represented by the phyla Actinobacteria, Proteobacteria, and Bacteroidetes (Newton et al., 2011). In addition, we have previously unveiled the vertical stratification of bacterioplankton communities in deep freshwater lakes, where the oxygenated hypolimnion - i.e., the deep aerobic water layer below the thermocline, which generally constitutes a volumetrically significant part of deep temperate, oligo-mesotrophic lakes - was dominated by specific lineages that are uncommon in the epilimnion, including members of Chloroflexi (Okazaki et al., 2013, 2018), Planctomycetes, Nitrospira and Thaumarchaeota (Okazaki and Nakano, 2016; Okazaki et al., 2017). These lineages are likely responsible for important biogeochemical processes in the oxygenated hypolimnion, such as remineralization or conversion of semi-labile organic matter (Maki et al., 2010; Thottathil et al., 2013), nitrification (Small et al., 2013; Alfreider et al., 2018), and methane oxidation (Murase and Sugimoto, 2005).

The recent introduction of viral metagenomics (viromics) opened the door to elucidating the vast diversity of uncultured viral genomes and genes (Brum and Sullivan, 2015) and facilitated identification of viruses infecting predominant bacterial hosts. Through both cultivation-dependent and -independent manners, viruses that infect major freshwater bacterioplankton lineages have been documented in the last few years, including those of Actinobacteria (Ghai et al., 2017), Polynucleobacter (Cabello-Yeves et al., 2017), LD28 (Ca. Methylopumilus) (Moon et al., 2017) and Comamonadaceae (Moon et al., 2018). Elucidating such predominant virus-host interactions is key to characterizing viruses playing central roles in the microbial ecosystem and biogeochemical cycling. 
However, despite a growing number of viromic studies in freshwater systems (Skvortsov et al., 2016; Moon et al., 2017; Silva et al., 2017; Arkhipova et al., 2018), viruses infecting other typical freshwater bacterioplankton lineages, such as LD12 (Ca. Fonsibacter) (Henson et al., 2018) and Limnohabitans (Kasalický et al., 2013) have yet to be characterized. Moreover, no viromic study has investigated an oxygenated hypolimnion, leaving hypolimnetic viral diversity and virus-host interactions totally unexplored.

The main aim of this study was to characterize key virus-host interactions in freshwater ecosystems. To this end, we performed spatiotemporal (from two water layers for nine months) sampling of both the cellular (size $=0.22-5.0 \mu \mathrm{m})$ and virion $(<0.22 \mu \mathrm{m})$ fractions at a pelagic station of a deep freshwater lake. This allowed simultaneous reconstruction of both viral and host (i.e., prokaryotic) genomes from the water column and to follow the lifecycles of individual viral lineages including both intra- and extra-cellular stages. The assembled genomes were compared with viral genomes derived from published metagenomic datasets, and the result demonstrated phylogeographic connectivity of the viral community among habitats. Overall, the present study provided an overview of genome-resolved viral diversity in freshwater systems and revealed virus-host interactions of potential ecological importance, including those involving ubiquitous freshwater bacterial lineages.

\section{Results and Discussion}

\section{Overview of samples and assemblies}

In total, 12 water samples were collected at a pelagic site on Lake Biwa, the largest freshwater lake in Japan. The epilimnion ( $5 \mathrm{~m}$ ) was sampled over 3 months and the hypolimnion $(65 \mathrm{~m})$ was sampled over 9 months. Water temperature, dissolved oxygen concentration, and the abundances of bacteria and virus-like particles in the study site (Table S1) were within the range reported from previous studies in the lake (Pradeep Ram et al., 2010; Okazaki et al., 2013). Notably, thermal stratification was observed from June to December and the hypolimnion was always oxygenated, with dissolved oxygen concentrations of $>6.0 \mathrm{mg} \mathrm{L}^{-1}$. Metagenomic sequencing with subsequent assembly (Table S2), decontamination, and dereplication steps eventually yielded 4,158 viral contigs of $>10 \mathrm{~kb}$ (Lake Biwa Viral Contigs [LBVCs]), including 183 complete (i.e., circular) genomes (Lake Biwa Viral Genomes [LBVGs]) (Fig. S1). The GC content of the 183 LBVGs ranged from 29.1 to $66.7 \%$, and all genome sizes were $<120 \mathrm{~kb}$ except for LBVG_1 (318 kb) and LBVG_2 (190 kb) (Fig. 1A), which were within the range of known prokaryotic dsDNA viral genomes (Mahmoudabadi and Phillips, 2018).

Similarity between viral genomes was evaluated using $S_{\mathrm{G}}$, a similarity measure (ranging from 0 to 1) based on genome-wide tBLASTx scores (Nishimura et al., 2017a). A previous study demonstrated that $S_{\mathrm{G}}>0.15$ was the best threshold for genus-level clustering of viral genomes (Nishimura et al., 2017a). Using this threshold, the 183 LBVGs were grouped into 28 genomic operational taxonomic units (gOTUs) containing 2-10 LBVGs each, leaving 90 LBVGs ungrouped

(Fig. 2). To assess the novelty or ubiquity of LBVGs, published viral genomic sequences were 
compiled into two databases - the Reference Viral Genome (RVG) and Environmental Viral Genome (EVG). The RVG included 2,621 isolated prokaryotic dsDNA viral genomes. The EVG included 2,860 metagenomically recovered viral genomes and manually collected viral genomes that had been reported to infect the dominant freshwater bacterioplankton lineages, including both isolated and metagenome-assembled genomes (Fig. S2). Using the threshold of $S_{\mathrm{G}}>0.15,4(2.2 \%)$ and $127(69.4 \%)$ LBVGs were found to have genus-level relatives in the RVG and EVG, respectively (Fig. 2). An $S_{\mathrm{G}^{-}}$ based proteomic tree including all LBVGs and EVGs and alignments among genomes is available at https://www.genome.jp/viptree/u/LBV/retree/LBVGandEVG.

Metagenomic binning of the contigs assembled from the cellular fraction recovered 57 metagenome-assembled genomes of bacterioplankton (Lake Biwa metagenome-assembled genomes [LBMAGs]), including diverse bacterial and archaeal phyla (Figs. 3 and S3). Forty-five (78.9\%) of these genomes were of high quality, with estimated completeness and contamination scores of $>80 \%$ and $<5 \%$, respectively (Table S3). Consistent with previous observations (Okazaki and Nakano, 2016; Okazaki et al., 2017), a depth-stratified bacterioplankton community was observed- members of LD12, Actinobacteria, and Cyanobacteria were dominant in the epilimnion, whereas CL500-11 and $C a$. Nitrosoarchaeum were dominant in the hypolimnion (Table S4). In several lineages (e.g., LD12, LD28, and OPB56), distinct genomes were recovered from the epilimnion and hypolimnion, indicating micro-diversification between the water layers. Two LBMAGs representing candidate phyla, $C a$. Levybacteria (OP11) and Ca. Saccharibacteria (TM7) (Brown et al., 2015), had not been reported in a previous study conducted at Lake Biwa using 16S rRNA gene amplicon sequencing (Okazaki and Nakano, 2016), as these phyla harbor 16S rRNA gene sequences that are undetectable with conventional universal primers.

\section{Spatiotemporal dynamics of the viral community}

Relative abundance of LBVGs and LBVCs was determined based on metagenomic read coverage, shown as fragments per kilobase per mapped million reads (FPKM) (Nishimura et al., 2017a; Yoshida et al., 2018). The result revealed that the epilimnion- and hypolimnion-specific viral lineages were clearly separated (Fig. 1B, C). Among the 183 LBVGs, 60 were epilimnion-specific and 62 were hypolimnion-specific, demonstrating epilimnion-hypolimnion preference $\left(P_{\text {epi }}\right)$ values of $>95 \%$ and $<5 \%$, respectively. Non-metric multidimensional scaling (NMDS) analysis further demonstrated vertical separation of the viral communities during the stratification period (Fig. 4). The depthstratified viral community is analogous to that reported from ocean (Hurwitz et al., 2015; Mizuno et al., 2016; Paez-Espino et al., 2016; López-Pérez et al., 2017; Luo et al., 2017) and likely reflects the depth-stratified community of bacterioplankton (Okazaki and Nakano, 2016) (Table S4).

The viral community was generally stable in the hypolimnion (the Bray-Curtis dissimilarity of the communities between consecutive months $=0.21-0.34$; except for September to October and December to January as discussed later) compared to the epilimnetic community (0.54-0.68) (Figs. 4 
and 5). The rapid succession of the viral community in the epilimnion was in line with previous studies (Rodriguez-Brito et al., 2010; Arkhipova et al., 2018). By contrast, in the hypolimnion, many viral lineages persistently dominated for more than a month (Fig. 5). Notably, the decay rate of virioplankton ranges from 0.14 to $54 \% \mathrm{~h}^{-1}$ (half-life $=0.9 \mathrm{~h}$ to 20.6 days) (Wommack and Colwell, 2000), meaning that most virions in the water column turn over within a month. In addition, a recent study in a marine system reported that the majority of metagenomically-detected viruses were transcriptionally active within a period of $24 \mathrm{~h}$ (Yoshida et al., 2018). Consequently, the continued dominance of some viral lineages in the hypolimnion likely resulted from the continuous production of virions, rather than their carryover for more than a month. This pattern might be attributable to the lower production of bacterioplankton in the hypolimnion, resulting in a prolonged viral lytic cycle. To support this, a previous study in Lake Biwa estimated that bacterial production was 10 -fold lower in the hypolimnion $\left(0.4 \pm 0.1 \mu \mathrm{g} \mathrm{Cl}^{-1} \mathrm{~d}^{-1}\right)$ than in the epilimnion $\left(4.2 \pm 3.2 \mu \mathrm{g} \mathrm{Cl}^{-1} \mathrm{~d}^{-1}\right)$, and the percentage of daily bacterial production lost to viruses was 4-fold lower in the hypolimnion $(13.6 \pm 5.2 \%)$ than in the epilimnion (52.7 $\pm 16.2 \%$ ) (Pradeep Ram et al., 2010).

In addition to the overall stability of the viral community in the hypolimnion, two dynamic community shifts were observed in the virion fraction, from September to October (Bray-Curtis dissimilarity $=0.54$ ) and from December to January (0.50) (Figs. 4 and 5). The first shift could be resulted from several viruses switching from lysogeny to lysis (i.e., induction). In the cellular fraction, LBVG_87 was the most abundant LBVG in September but its abundance decreased abruptly in October, whereas its abundance in the virion fraction increased 120 -fold over the same period, making LBVG_87 the most abundant virioplankton (Figs. 5, S4 and S5). Similarly, the relative abundances of LBVG_111 and LBVG_121 in the virion fraction increased >1800-fold and 38-fold from September to October, respectively, likely due to the induction of abundant intracellular viruses in September (Figs. 5, S4 and S5). Regrettably, the host for LBVG_87, LBVG_111, and LBVG_121 could not be identified. Since no integrase gene was found in their genomes, they may have existed in a host's cell in an extrachromosomal or pseudolysogenic manner. As proposed for the deep ocean (Weinbauer et al., 2003; Paul, 2008; Mizuno et al., 2016; Luo et al., 2017), the lysogenic strategy in deeper water likely results from low bacterioplankton productivity, which is insufficient to support lytic viral propagation. Lytic induction can be triggered by environmental stressors such as $\mathrm{pH}$, temperature, nutrients, oxidative stress, and solar radiation (Weinbauer, 2004; Howard-Varona et al., 2017). While the hypolimnion during stratification period is more physicochemically stable than the epilimnion, biological factors, e.g., a pulse of sinking phytoplankton cells from the epilimnion (Kagami et al., 2006), could have resulted in a monthly-scale environmental shift and triggered the induction in the hypolimnion. Induction can also be trigged by the increasing cell abundance or improved physiological condition of the host, with the virus acting as a "time bomb" and breaking the symbiotic relationship with their host once the host has successfully bloomed in the environment (Paul, 2008; 
Brum et al., 2016). Indeed, hypolimnion-specific bacterial lineages often take months to archive their peak abundance (Okazaki et al., 2013, 2018; Okazaki and Nakano, 2016), suggesting that lysogeny (or presudolysogeny) is preferred strategy for viruses during the long growth phase of the host. No difference in cellular-virion preference $\left(P_{\text {cell }}\right)$ was observed between water layers (Fig. S6). Thus, lysogeny and induction may also be a common strategy in the epilimnion, although temporal trends were not clearly observed in that layer, presumably due to the rapid succession of the epilimnetic virion community (Figs. 4 and 5), which could not be fully resolved through monthly monitoring.

The second shift in the virion community from December to January likely resulted from the onset of winter vertical mixing (Table S1), which intermingled the epilimnetic and hypolimnetic viral communities, as observed for bacterioplankton (Okazaki et al., 2013, 2018; Okazaki and Nakano, 2016). Alternatively, environmental stresses associated with the mixing event (e.g., increased solar radiation) could have induced lysogens in the lytic cycle (Winter et al., 2018) and resulted in the observed viral community shift.

\section{Possible metabolic reprogramming of hosts by viral AMGs}

Functional annotation of viral genes (Supplementary Dataset S1) revealed that LBVGs encoded AMGs that have previously been identified in marine viromes (Hurwitz et al., 2015; Hurwitz and U'Ren, 2016). For example, two cyanobacterial viruses (LBVG_2 and LBVG_12) harbored the photosystem II D1 protein ( $p s b A$ ) gene, which accelerates the host's photosynthetic light reaction rates to facilitate viral propagation. LBVG_55, one of the dominant viruses in the hypolimnion with an unknown host (Fig. 5), encoded genes (cobS and cobT) involved in the biosynthesis of cobalamin, which is often absent from bacterial genomes, thus limiting their metabolic capability (Shelton et al., 2019). Several LBVGs harbored a cluster of genes involved in the biosynthesis of lipopolysaccharides (LPS) and capsular polysaccharides. For example, LBVG_26 encoded genes involved in the biosynthesis of Nacetylneuraminic acid (nеuA, nеuB, and $n е u C$ ), in addition to genes annotated as encoding putative sugar epimerase (capD), amidotransferase ( $p s e A)$, aminotransferase ( $p g l C)$, and acyltransferase $(p g l D)$. These genes may alter the cell surface properties of their hosts to prevent infection with other viruses (Sullivan et al., 2005) or to provide tolerance to temperature, oxidative stress, or antibiotics (Nishimura et al., 2017a). Proteins in the adenylyl-sulfate kinase (CysC) and 3'-phosphoadenosine 5'phosphosulfate (PAPS) reductase (CysH) families were encoded in 4 and 17 LBVGs, respectively, and LBVG_98 contained both (Supplementary Dataset S1). These genes are involved in assimilatory sulfate reduction and likely facilitate the host's utilization of reduced sulfur compounds (Summer et al., 2007; Mizuno et al., 2013a). These genes are present in ubiquitous and abundant viral groups (e.g., gOTU_3 and gOTU_11), indicating that they are quantitatively significant in the ecosystem. By contrast, these genes were not reported as common AMGs in marine ecosystems (Hurwitz et al., 2015; Hurwitz and U'Ren, 2016). Given that freshwater systems are sulfur-limited, and that the genomes of many predominant freshwater bacterioplankton lineages such as LD12 (Eiler et al., 2016; Henson et 
al., 2018), acI-B1 (Neuenschwander et al., 2018), and CL500-11 (Mehrshad et al., 2018) lack the complete pathway for assimilatory sulfate reduction, these viral-encoded genes are likely key factors modulating microbial sulfur metabolism in the lake.

\section{Ecological role of viruses infecting the dominant bacterioplankton}

Leveraged by the simultaneously reconstructed bacterioplankton genomes (LBMAGs), hosts were predicted for 40 LBVGs. The predicted hosts spanned 10 phyla (or Proteobacteria classes; Fig. 3), and the host of 6 LBVGs could be further resolved to the genus level (Table S5). Notably, we identified 13 LBVGs infecting Actinobacteria, which is one of the most diverse, abundant, and ubiquitous groups of freshwater bacterioplankton (Newton et al., 2011). Aside from LBVG_68 (genome size $=40.0 \mathrm{~kb}$ ), all actinoviral LBVGs had small genomes (14.0-19.8 kb) and formed a monophyletic clade composed of four gOTUs (gOTU_8, gOTU_13, gOTU_14, and gOTU_28; Fig. 2). Their monophyly was further supported by the proteomic tree including EVGs (https://www.genome.jp/viptree/u/LBV/retree/LBVGandEVG). All of them were closely related to viral genomes of the same size that originated from other freshwater systems (Fig. 6 and Supplementary Alignment S1). The members of gOTU_28 were relatives of the G4 actinophage (uvFW-CGR-AMDFOS-S50-C341) (Fig. 6), one of four actinoviral groups revealed metagenomically in a Spanish reservoir (Ghai et al., 2017). Relatives of the other three Spanish actinoviral groups (G1, G2, and G3) were absent from our LBVGs but were observed among LBVCs (Fig. S7) and EVGs recovered from other freshwater lakes (Supplementary Alignment S2-4). Together, the results suggest that these actinoviral groups are ubiquitous in freshwater systems. Their broad range of GC contents (41.6-62.6\%) suggests that their hosts include diverse members of Actinobacteria that also exhibit a wide range of GC contents (Table S3). In the epilimnion, LBVG_179 consecutively predominated and other actinoviral members also abundant in both the cellular and virion fractions (Figs. 5 and S8). Although data after September were not available in the epilimnion, the actinoviral predominance in the virion fraction after the onset of the mixing period (i.e., in the hypolimnion on January) implies that they were continuously dominated in the epilimnetic water until the end of stratification period. These results suggest that diverse members of actinovirus actively replicating and lysing the host cells to produce virions in the epilimnion. This finding is intriguing given the predominance of Actinobacteria and evokes the "King of the Mountain" (KoM) hypothesis, which was proposed to explain the co-dominance of marine Pelagibacter and its viruses (Giovannoni et al., 2013). In the KoM hypothesis, the predominance of the host species under high viral lytic pressure provides a greater chance for the host to acquire resistance against viral infection through genomic recombination, and this generates a positive feedback loop for host propagation. Supporting this hypothesis, singlecell amplified genomes of acI, the most representative freshwater Actinobacterial lineage, exhibited high intra-population diversification, suggesting that acI members have a high recombination rate (Garcia et al., 2018). Another study revealed that members of the acI lineage commonly harbor 
genomic islands containing genes that may be involved in viral host recognition (e.g., extracellular structural genes), even among closely related strains (average nucleotide identity [ANI] >97\%) inhabiting the same lake (Neuenschwander et al., 2018). Accordingly, the most closely related pair of actinoviral LBVGs in the present study (LVBG_169 and LBVG_172; $S_{\mathrm{G}}=0.91, \mathrm{ANI}=96.4 \%$ ) showed diversification in tail-related genes (e.g., tape measure protein), which are often involved in viral recognition of the host cell surface (Mizuno et al., 2014; Rodriguez-Valera et al., 2014) (Supplementary Alignment S1). Moreover, the streamlined acI genomes do not harbor the CRISPRCas system (Neuenschwander et al., 2018), and a recent meta-epigenomic analysis conducted at Lake Biwa demonstrated that the genomes of Actinobacteria lack both methylated DNA motifs and methyltransferase genes (Hiraoka et al., 2019), implying that they lack the restriction-modification system for resisting viral infection. These findings further support the KoM hypothesis, which assumes that the host prefers a strategy to overcome resource competition rather than act as a defense specialist (Giovannoni et al., 2013). In light of this hypothesis, the high abundance and diversity of actinoviruses may result from an arms race with their hosts, leading to genomic diversification of the hosts to avoid mortality induced by a high viral load. It should be noted that such microdiversification of viral genomes poses challenges for metagenomic assembly (Martinez-Hernandez et al., 2017; Roux et al., 2017b; Warwick-Dugdale et al., 2019); indeed, 109 LBVCs encoded the actinoviral hallmark whiB gene (Supplementary Dataset S1), suggesting that the majority of actinoviral genomes were not recovered as LBVGs (i.e., circularly assembled). Although further investigation is beyond the scope of the present study, our results revealed that, analogous to their hosts, actinoviruses are one of the most diverse, abundant, ubiquitous, and active viral groups in freshwater systems.

LD12 ( $\mathrm{Ca}$. Fonsibacter) is a freshwater division of the SAR11 lineage (Pelagibacteraceae), which is one of the most ubiquitous and abundant bacterioplankton in freshwater, as is the case for its marine counterparts (Salcher et al., 2011; Henson et al., 2018). Indeed, LD12 was by far the most abundant LBMAG in the epilimnion throughout the study period (Table S4). Unlike actinoviruses, the three predicted LD12 viruses were not clustered with other LBVGs (Fig. 2) and thus their genomic diversification seems limited, possibly reflecting the fact that LD12 bacteria also show limited genomic diversification (Zaremba-Niedzwiedzka et al., 2013; Garcia et al., 2018). Among these LBVGs, LBVG_1 was the largest $(317.9 \mathrm{~kb})$ viral genome assembled in the present study. LBVG_1 encoded many genes closely related to those of Pelagibacterales, including the $30 \mathrm{~S}$ ribosomal protein S21, which is the most abundant virus-encoded ribosomal protein in aquatic systems and presumably facilitates takeover of the host's translational machinery (Mizuno et al., 2019) (Supplementary Dataset S1). A BLASTp search against the NCBI RefSeq database revealed that LBVG_1 showed high similarity to another large (genome size $=490 \mathrm{~kb}$ ) alphaproteobacterial (Agrobacterium) phage Atu_ph07 (Attai et al., 2018) in their jumbo phage marker genes (Yuan and Gao, 2017): terminase large subunit (amino acid sequence identity $=52.6 \%$ ), major capsid protein $(58.3 \%$ ), and DNA 
polymerase family B (43.8\%). These results suggest that LBVG_1 is a jumbo phage infecting the LD12 lineage. LBVG_1 was abundant in the cellular fraction in the epilimnion but rare in the virion fraction (Figs. 5 and S8). However, it is possible that their planktonic virions could have been included in the cellular fraction, because large virions of jumbo phage may be captured by the $0.22 \mu \mathrm{m}$ poresized filter (Yuan and Gao, 2017). By contrast, the two other predicted LD12 viruses (LBVG_76 and LBVG_174) were abundant in both the cellular and virion fractions (Figs. 5 and S8), suggesting that these viruses were actively replicating and lysing their hosts. These results indicate that, in accordance with their marine counterparts, viruses are an important driving factor for the population dynamics of LD12, which is one of the most quantitatively significant components of freshwater microbial ecosystems.

The present study recovered a LBMAG of $\mathrm{Ca}$. Nitrosoarchaeum (Fig. 3), which is a member of the ammonia-oxidizing, chemoautotrophic archaeal taxon Marine Group I (MGI). Members of MGI dominate the hypolimnion of deep freshwater lakes (Okazaki et al., 2017) (Table S4) and thus are important players in the nitrogen and carbon cycles of lakes. In marine systems, members of MGI are also dominant in the deep aphotic layer, and recent studies have reported the presence of several putative MGI viruses (Chow et al., 2015; Labonté et al., 2015), including those encoding AMGs such as amoC (Ahlgren et al., 2019) and cobS (López-Pérez et al., 2018). The present study predicted one $\mathrm{Ca}$. Nitrosoarchaeum virus (LBVG_51), the first freshwater MGI virus to our knowledge. The virus did not show genomic similarities to known marine MGI viruses or to any genomes in the EVG database. The genome encoded RadA-like ATPase, replication protein A and minichromosomemaintenance helicase genes, which drive the archaeal DNA replication system (Zatopek et al., 2018), presumably to facilitate viral genomic replication in the host (Krupovic et al., 2018). LBVG_51 was mainly detected in the cellular fraction in the hypolimnion (Figs. 5 and S8), suggesting that they were intracellular during the study period. While the relative abundances of the virus (LBVG_51) and the host (Ca. Nitrosoarchaeum) both showed a continuously increasing trend in the hypolimnion during the stratification period, the viral abundance increased disproportionally faster (48.3-fold from September to December) than that of the host (2.4-fold) (Supplementary Dataset S1 and Table S4). No integrase gene was annotated in the LBVG_51 genome. Collectively, we hypothesize that LBVG_51 genomes were replicating extrachromosomally in cells of the host using the replication machinery encoded on the viral genome. A previous study reported an abrupt drop in $\mathrm{Ca}$. Nitrosoarchaeum abundance after the onset of the mixing period (Okazaki and Nakano, 2016), but no evidence for mass induction was found in the present study. We further speculated that one incomplete contig, LVBC_1935 (16,737 bp), might also be derived from a $\mathrm{Ca}$. Nitrosoarchaeum virus, as it encoded multiple archaeal genes and exhibited a GC content and spatiotemporal distribution corresponding to those of $C a$. Nitrosoarchaeum (Supplementary Dataset S1).

Viruses infecting other bacterioplankton taxa, namely Cyanobacteria, Bacteroidetes, 
Betaproteobacteria, Gammaproteobacteria, Nitrospira, Planctomycetes, and Verrucomicrobia were also predicted (Figs. 2 and 3). Most of these virus-host pairs were novel, and their potential interaction with hosts is discussed in Supplementary Results and Discussion.

\section{Viral genomic diversification among habitats}

Majority (116 of 183) of the LBVGs were closely related to genomes that were recovered from other freshwater habitats (Fig. 2), indicating that they belonged to ubiquitous freshwater viral lineages. Some of these lineages exhibited remarkably high inter-lake genomic similarities. For example, among actinoviruses (Fig. 6), LBVG_182 and 3300002835.a_100013722, a genome retrieved from Lake Mendota, USA (Roux et al., 2017a), exhibited an $S_{\mathrm{G}}$ value of 0.76 and an ANI value of $84 \%$ (Supplementary Alignment S1). Moreover, LBVG_144 and Soyang_Oct2014_scaffold_160, which has an unknown host, exhibited an $S_{\mathrm{G}}$ value of 0.94 and an ANI value of $99 \%$ (Supplementary Alignment S5). Whereas nearly identical viral genomes have been reported from distant locations in marine environments, such as the Mediterranean Sea and Pacific Ocean (Rodriguez-Valera et al., 2014), these results in freshwater systems are intriguing, as lakes and reservoirs are physically isolated from one another. By contrast, the genomes of their host (i.e., bacterioplankton) inhabiting different freshwater systems are generally distinct (Hahn et al., 2016; Kang et al., 2017; Garcia et al., 2018; Neuenschwander et al., 2018), although highly similar genomes (ANI $>95 \%$ ) have occasionally been reported from lakes on different continents (Mehrshad et al., 2018). The high phylogeographic connectivity of viruses was presumably because viruses can easily colonize a new habitat due to the lack of immunity by local hosts, whereas colonization by bacteria is often constrained by the priority effect, that is, occupation of the niche by prior inhabitants limits settlement of newly migrated genotypes (Incagnone et al., 2015).

Aside from this evidence of connectivity among freshwater habitats, we also observed 34 LBVGs that were similar $\left(S_{\mathrm{G}}>0.15\right)$ to marine viral genomes (Fig. 2). For example, gOTU_26 (LBVG_135 and LBVG_162)—one of the dominant viruses in the hypolimnion with an unidentified host (Fig. 5) - had a conserved genomic structure with viral genomes originating from a broad range of aquatic habitats; surface and deep waters of the Mediterranean Sea, Pacific Ocean, Atlantic Ocean, Arabian Sea, Osaka Bay, Lake Neagh and Lake Soyang (Supplementary Alignment S6). As observed for cyanoviruses (Dreher et al., 2011; Chénard et al., 2015), close phylogenetic relationships among marine and freshwater viruses suggest that their hosts are bacterioplankton belonging to taxa containing both marine and freshwater members, such as Pelagibacteriaceae (Eiler et al., 2016), Methylophilaceae (Salcher et al., 2015), and Flavobacteriaceae (Eiler and Bertilsson, 2007). Indeed, LBVG_76 and LBVG_174, which are putative LD12 viruses, share genomic structures with marine SAR11 phages recovered from Mediterranean viromes (Mizuno et al., 2013b, 2016) and the Tara Oceans Virome (Brum et al., 2015) (Supplementary Alignments S7 and S8). A recent study (Paver et al., 2018) has challenged the idea that marine-freshwater transitions by bacterioplankton are infrequent 
(Logares et al., 2009; Eiler et al., 2016), and viral diversification processes that allow crossing of this salt divide in association with their hosts are an intriguing research topic. Notably, the greatest similarity between marine and freshwater viral genomes was observed among members of the Synechococcus viruses S-EIV1, LBVG_9 and TARA_ERS488929_N000037 (collected at a pelagic site in the Arabian Sea), which exhibited higher similarity scores $\left(S_{\mathrm{G}}=0.52\right)$ than among those collected in freshwater systems or even within the same lake (Supplementary Alignment S9). Thus, in the diversification processes of at least some viral lineages, the transition between marine and freshwater habitats appears to be a relatively frequent event, presumably because viruses require less modification in their genetic machinery to cross the salt divide.

\section{Experimental Procedures}

\section{Sample collection, sequencing, and assembly}

Details of the sample collection, sequencing, and assembly procedures are available in Supplementary Materials and Methods and Figure S1. Briefly, the cellular fraction $(0.22-5.0 \mu \mathrm{m})$ was obtained shipboard through filtration of the water sample. The virion fraction $(<0.22 \mu \mathrm{m})$ was collected from filtered water by concentrating virions using iron(III) chloride flocculation (John et al., 2011), followed by purification using $\mathrm{CsCl}$ density gradient ultracentrifugation (Hurwitz et al., 2013). After DNA extraction and library preparation for shotgun metagenomics, two sequencing runs $(2 \times 300 \mathrm{bp})$ were performed using the Illumina MiSeq system for each of the cellular and virion fractions. The sequence reads generated were (co-)assembled using metaSPAdes v. 3.10 .1 (Nurk et al., 2017) for the cellular fraction and SPAdes v. 3.9.0 (Bankevich et al., 2012) for the virion fraction (Table S2).

\section{Extraction of viral contigs}

Viral contigs were extracted from 11 (co-)assemblies from the virion fraction and 7 assemblies from the cellular fraction (Table S2). Only contigs longer than $10 \mathrm{kbp}$ were considered for subsequent analysis. Identification of viral contigs was performed with VirSorter v. 1.0.3 (Roux et al., 2015) using Virome Decontamination mode with reference to the Virome Database, and all contigs assigned to categories 1-3 (virus and prophage) were extracted. The resulting 8,173 contigs were inspected for redundancy using BLASTn searches against themselves with NCBI-BLAST+ v. 2.7.1 (Camacho et al., 2009), where all $>500 \mathrm{nt}$ high-scoring segment pairs were considered, contigs with $>95 \%$ nucleotide identity across $>80 \%$ of the contig length (Roux et al., 2017b) were identified as redundant, and the shorter contig in the pair was discarded. The resulting 4,315 contigs were further decontaminated through inspection for viral hallmark genes. To this end, 134,388 open reading frames (ORFs) on 4,315 contigs were predicted with Prodigal v. 2.6.3 (Hyatt et al., 2010) and functionally annotated (see Supplementary Materials and Methods for functional annotation workflow). Genes annotated as encoding terminase, tail, capsid or portal proteins were regarded as viral hallmark genes. Among contigs with no viral hallmark genes, those annotated as prophages using VirSorter (i.e., containing cellular hallmark genes) and those exclusively detected in the cellular fraction based on 
read coverage were regarded as bacterial genomic contaminants and were removed. Consequently, 4,158 contigs (LBVCs) were retained. Further, 183 complete (i.e., circular) genomes (LBVGs) were identified using ccfind v. 1.1 (https://github.com/yosuken/ccfind) (Nishimura et al., 2017a). Handling of FASTA files and calculations of genome size and GC contents were performed using SeqKit v. 0.5.0 (Shen et al., 2016).

\section{Abundance estimation based on metagenomic read coverage}

The relative abundance (as metagenomic read coverage shown by FPKM) of LBVGs in each sample was calculated using the CountMappedReads v. 1.0 script (https://github.com/yosuken/CountMappedReads). Habitat preference for the epilimnion over the hypolimnion $\left(P_{\text {epi }}\right)$ was measured as the quotient of abundance in the epilimnion versus the sum of abundance in the epilimnion and hypolimnion (i.e., epilimnion/[epilimnion + hypolimnion]), and habitat preference for the cellular fraction over the virion fraction $\left(P_{\text {cell }}\right)$ was measured as the quotient of abundance in the cellular fraction versus the sum of abundance in the cellular and virion fractions (i.e., cellular/[cellular + virion]). Note that only samples for which both virion and cellular fractions were available (i.e., July-September in the epilimnion and September-December in the hypolimnion) were considered for this calculation.

\section{Binning of prokaryotic genomes}

Binning of prokaryotic genomes was performed with MetaBAT v. 0.32 .5 (Kang et al., 2015) using the (co-) assemblies from the cellular fraction, and the output was manually curated (Fig. S1 and Table S2; see Supplementary Materials and Methods for details). Phylogenetic assignment of the resulting 57 bins (LBMAGs) was carried out by drawing a phylogenetic tree with published freshwater bacterioplankton genomes using PhyloPhlAn v. 0.99 (Segata et al., 2013) and the assignments were confirmed using GTDB-Tk v. 0.2.1 with reference to the release 86 database (Parks et al., 2018). The relative abundance of LBMAGs in each sample was calculated using the CountMappedReads v. 1.0 script.

\section{Construction of reference databases}

The RVG and EVG databases were originally described by Nishimura et al. (2017a) and were updated in the present study (Fig. S2). The RVG was prepared by extracting 2,621 genomes of isolated dsDNA prokaryotic viruses from the Virus-Host Database (as of Feb. 6, 2018) (Mihara et al., 2016). The EVG was built based on 1,811 genomes compiled for the previous study (Nishimura et al., 2017a) and augmented with the following datasets: (i) 125,842 mVCs (metagenomic Viral Contigs), which were generated from metagenomes deposited in the IMG/M database (Paez-Espino et al., 2016); (ii) 28 complete viral genomes retrieved from a Mediterranean deep-ocean virome (Mizuno et al., 2016); (iii) contigs assembled from six viromes collected seasonally from Lake Soyang (PRJEB15535) (Moon et al., 2017); (iv) 488 contigs previously compiled from published freshwater viromes (Arkhipova et al., 2018); and (v) 313 complete viral genomes recovered from Lake Neagh (Arkhipova et al., 2018). In 
addition, the genomes of recently reported freshwater viruses, including the Synechococcus virus SEIV1 (Chénard et al., 2015), eight actinoviruses (Ghai et al., 2017), a LD28 virus (Moon et al., 2017), two Comamonadaceae viruses (Moon et al., 2018), and a Polynucleobacter virus (Cabello-Yeves et al., 2017) were compiled. Assembly of the Lake Soyang virome was performed using the same parameters used for the Lake Biwa virome. The contigs were inspected for circularity using ccfind $\mathrm{v}$. 1.1. Only $>10 \mathrm{~kb}$ complete genomes were retained and dereplicated using the BLASTn search against themselves, where all $>500 \mathrm{nt}$ high-scoring segment pairs were considered and those with $>99 \%$ nucleotide identity across $>95 \%$ of their length were identified as duplicates. The resulting EVG database included 2,860 viral genomes.

\section{Phylogenetic analysis of viral genomes}

Calculation of $S_{\mathrm{G}}$ and construction of a $S_{\mathrm{G}}$-based proteomic tree were performed using ViPTreeGen v. 1.1.1, a standalone version of ViPTree (Nishimura et al., 2017b). LBVGs were searched against the RVG and EVG databases using the 2D mode of ViPTreeGen v. 1.1.1, and the number of hits with $S_{\mathrm{G}}$ $>0.15$ was determined for each LBVG.

\section{Host prediction}

The host of each LBVG was predicted from combinations of in silico analyses (Edwards et al., 2016). Briefly, the host of an LBVG was predicted when a close relative infected a known host, a taxonspecific marker gene was found, $>80 \%$ of annotated bacterial genes were taxonomically related to a single taxon, or the virus and host genomes shared a $>30$ bp nucleotide sequence segment. See Supplementary Materials and Methods for a detailed workflow.

\section{Data availability}

Raw reads from the cellular and virion fractions were deposited under accession numbers PRJDB6644 and PRJDB7309, respectively. LBMAGs were deposited under the BioSample identifiers SAMD00166046-00166102. The nucleotide sequences of the LBVGs, LBVCs, RVG, and EVG are available from https://doi.org/10.6084/m9.figshare.7934924.

\section{Acknowledgments}

This work was supported by JSPS KAKENHI (Nos. 15J00971, 16H06429, 16K21723, 16H06437, 17H03850, 17K19289, and 18J00300), the Environment Research and Technology Development Fund (No. 5-1607) of the Ministry of the Environment, Japan, and the Canon Foundation (No. 203143100025). Computation time was provided by the SuperComputer System, Institute for Chemical Research, Kyoto University. Field sampling on Lake Biwa was conducted using the research vessel Hasu belonging to the Center for Ecological Research, Kyoto University, and supported by Y. Goda and T. Akatsuka. We are grateful to T. Narihiro and M. K. Nobu for their helpful advice about metagenomic analysis, and to H. Watai, N. Haruki, and M. Yamanaka for their assistance in sample preparation. We thank K. Arkhipova and K. Moon for providing the original datasets from their published works. 


\section{Competing Interests}

The authors declare no conflict of interests.

\section{References}

Ahlgren, N.A., Fuchsman, C.A., Rocap, G., and Fuhrman, J.A. (2019) Discovery of several novel, widespread, and ecologically distinct marine Thaumarchaeota viruses that encode amoC nitrification genes. ISME J 13: 618-631.

Alfreider, A., Grimus, V., Luger, M., Ekblad, A., Salcher, M.M., and Summerer, M. (2018) Autotrophic carbon fixation strategies used by nitrifying prokaryotes in freshwater lakes. FEMS Microbiol Ecol 94: $1-12$.

Arkhipova, K., Skvortsov, T., Quinn, J.P., McGrath, J.W., Allen, C.C.R., Dutilh, B.E., et al. (2018) Temporal dynamics of uncultured viruses: a new dimension in viral diversity. ISME J 12: 199-211.

Attai, H., Boon, M., Phillips, K., Noben, J.-P., Lavigne, R., and Brown, P.J.B. (2018) Larger Than Life: Isolation and Genomic Characterization of a Jumbo Phage That Infects the Bacterial Plant Pathogen, Agrobacterium tumefaciens. Front Microbiol 9: 1-14.

Bankevich, A., Nurk, S., Antipov, D., Gurevich, A.A., Dvorkin, M., Kulikov, A.S., et al. (2012) SPAdes: A New Genome Assembly Algorithm and Its Applications to Single-Cell Sequencing. J Comput Biol 19: 455-477.

Bergh, Ø., BØrsheim, K.Y., Bratbak, G., and Heldal, M. (1989) High abundance of viruses found in aquatic environments. Nature 340: 467-468.

Breitbart, M., Thompson, L., Suttle, C., and Sullivan, M. (2007) Exploring the Vast Diversity of Marine Viruses. Oceanography 20: 135-139.

Brown, C.T., Hug, L.A., Thomas, B.C., Sharon, I., Castelle, C.J., Singh, A., et al. (2015) Unusual biology across a group comprising more than 15\% of domain Bacteria. Nature 523: 208-211.

Brum, J.R., Hurwitz, B.L., Schofield, O., Ducklow, H.W., and Sullivan, M.B. (2016) Seasonal time bombs: dominant temperate viruses affect Southern Ocean microbial dynamics. ISME J 10: 437449 .

Brum, J.R., Ignacio-Espinoza, J.C., Roux, S., Doulcier, G., Acinas, S.G., Alberti, A., et al. (2015) Patterns and ecological drivers of ocean viral communities. Science (80- ) 348: 1261498-1261498.

Brum, J.R. and Sullivan, M.B. (2015) Rising to the challenge: accelerated pace of discovery transforms marine virology. Nat Rev Microbiol 13: 147-159.

Cabello-Yeves, P.J., Zemskaya, T.I., Rosselli, R., Coutinho, F.H., Zakharenko, A.S., Blinov, V. V, and Rodriguez-Valera, F. (2017) Genomes of Novel Microbial Lineages Assembled from the Sub-Ice Waters of Lake Baikal. Appl Environ Microbiol 84: e02132-17.

Camacho, C., Coulouris, G., Avagyan, V., Ma, N., Papadopoulos, J., Bealer, K., and Madden, T.L. (2009) BLAST plus: architecture and applications. BMC Bioinformatics 10: 1.

Chénard, C., Chan, A.M., Vincent, W.F., and Suttle, C.A. (2015) Polar freshwater cyanophage S-EIV1 
represents a new widespread evolutionary lineage of phages. ISME J 9: 2046-2058.

Chow, C.-E.T., Winget, D.M., White, R.A., Hallam, S.J., and Suttle, C.A. (2015) Combining genomic sequencing methods to explore viral diversity and reveal potential virus-host interactions. Front Microbiol 6: 265.

Dreher, T.W., Brown, N., Bozarth, C.S., Schwartz, A.D., Riscoe, E., Thrash, C., et al. (2011) A freshwater cyanophage whose genome indicates close relationships to photosynthetic marine cyanomyophages. Environ Microbiol 13: 1858-1874.

Edwards, R.A., McNair, K., Faust, K., Raes, J., and Dutilh, B.E. (2016) Computational approaches to predict bacteriophage-host relationships. FEMS Microbiol Rev 40: 258-272.

Eiler, A. and Bertilsson, S. (2007) Flavobacteria Blooms in Four Eutrophic Lakes: Linking Population Dynamics of Freshwater Bacterioplankton to Resource Availability. Appl Environ Microbiol 73: 3511-3518.

Eiler, A., Mondav, R., Sinclair, L., Fernandez-Vidal, L., Scofield, D.G., Schwientek, P., et al. (2016) Tuning fresh: radiation through rewiring of central metabolism in streamlined bacteria. ISME J 10: 1902-1914.

Garcia, S.L., Stevens, S.L.R., Crary, B., Martinez-Garcia, M., Stepanauskas, R., Woyke, T., et al. (2018) Contrasting patterns of genome-level diversity across distinct co-occurring bacterial populations. ISME J 12: 742-755.

Ghai, R., Mehrshad, M., Mizuno, C.M., and Rodriguez-Valera, F. (2017) Metagenomic recovery of phage genomes of uncultured freshwater actinobacteria. ISME J 11: 304-308.

Giovannoni, S., Temperton, B., and Zhao, Y. (2013) Giovannoni et al. reply. Nature 499: E4-E5.

Hahn, M.W., Jezberová, J., Koll, U., Saueressig-Beck, T., and Schmidt, J. (2016) Complete ecological isolation and cryptic diversity in Polynucleobacter bacteria not resolved by 16S rRNA gene sequences. ISME J 10: 1642-1655.

Henson, M.W., Lanclos, V.C., Faircloth, B.C., and Thrash, J.C. (2018) Cultivation and genomics of the first freshwater SAR11 (LD12) isolate. ISME J 12: 1846-1860.

Hiraoka, S., Okazaki, Y., Anda, M., Toyoda, A., Nakano, S., and Iwasaki, W. (2019) Metaepigenomic analysis reveals the unexplored diversity of DNA methylation in an environmental prokaryotic community. Nat Commun 10: 159.

Howard-Varona, C., Hargreaves, K.R., Abedon, S.T., and Sullivan, M.B. (2017) Lysogeny in nature: mechanisms, impact and ecology of temperate phages. ISME J 11: 1511-1520.

Hurwitz, B.L., Brum, J.R., and Sullivan, M.B. (2015) Depth-stratified functional and taxonomic niche specialization in the 'core' and 'flexible' Pacific Ocean Virome. ISME J 9: 472-484.

Hurwitz, B.L., Deng, L., Poulos, B.T., and Sullivan, M.B. (2013) Evaluation of methods to concentrate and purify ocean virus communities through comparative, replicated metagenomics. Environ Microbiol 15: 1428-1440. 
Hurwitz, B.L. and U'Ren, J.M. (2016) Viral metabolic reprogramming in marine ecosystems. Curr Opin Microbiol 31: 161-168.

Hyatt, D., Chen, G.-L., LoCascio, P.F., Land, M.L., Larimer, F.W., and Hauser, L.J. (2010) Prodigal: prokaryotic gene recognition and translation initiation site identification. BMC Bioinformatics 11: 119.

Incagnone, G., Marrone, F., Barone, R., Robba, L., and Naselli-Flores, L. (2015) How do freshwater organisms cross the "dry ocean"? A review on passive dispersal and colonization processes with a special focus on temporary ponds. Hydrobiologia 750: 103-123.

Jenny, J., Normandeau, A., Francus, P., Ecaterina, Z., and Gregory-eaves, I. (2016) Urban point sources of nutrients were the leading cause for the historical spread of hypoxia across European lakes. 113: $1-6$.

John, S.G., Mendez, C.B., Deng, L., Poulos, B., Kauffman, A.K.M., Kern, S., et al. (2011) A simple and efficient method for concentration of ocean viruses by chemical flocculation. Environ Microbiol Rep 3: 195-202.

Kagami, M., Gurung, T.B., Yoshida, T., and Urabe, J. (2006) To sink or to be lysed? Contrasting fate of two large phytoplankton species in Lake Biwa. Limnol Oceanogr 51: 2775-2786.

Kang, D.D., Froula, J., Egan, R., and Wang, Z. (2015) MetaBAT, an efficient tool for accurately reconstructing single genomes from complex microbial communities. PeerJ 3: e1165.

Kang, I., Kim, S., Islam, M.R., and Cho, J.-C. (2017) The first complete genome sequences of the acI lineage, the most abundant freshwater Actinobacteria, obtained by whole-genome-amplification of dilution-to-extinction cultures. Sci Rep 7: 42252.

Kasalický, V., Jezbera, J., Hahn, M.W., and Šimek, K. (2013) The Diversity of the Limnohabitans Genus, an Important Group of Freshwater Bacterioplankton, by Characterization of 35 Isolated Strains. PLoS One 8: e58209.

Koskella, B. and Brockhurst, M.A. (2014) Bacteria-phage coevolution as a driver of ecological and evolutionary processes in microbial communities. FEMS Microbiol Rev 38: 916-931.

Krupovic, M., Cvirkaite-Krupovic, V., Iranzo, J., Prangishvili, D., and Koonin, E. V. (2018) Viruses of archaea: Structural, functional, environmental and evolutionary genomics. Virus Res 244: 181-193.

Labonté, J.M., Swan, B.K., Poulos, B., Luo, H., Koren, S., Hallam, S.J., et al. (2015) Single-cell genomics-based analysis of virus-host interactions in marine surface bacterioplankton. ISME J 9: 2386-2399.

Logares, R., Bråte, J., Bertilsson, S., Clasen, J.L., Shalchian-Tabrizi, K., and Rengefors, K. (2009) Infrequent marine-freshwater transitions in the microbial world. Trends Microbiol 17: 414-422.

López-Pérez, M., Haro-Moreno, J.M., Gonzalez-Serrano, R., Parras-Moltó, M., and Rodriguez-Valera, F. (2017) Genome diversity of marine phages recovered from Mediterranean metagenomes: Size matters. PLOS Genet 13: e1007018. 
López-Pérez, M., Haro-Moreno, J.M., de la Torre, J.R., and Rodriguez-Valera, F. (2018) Novel

Caudovirales associated with Marine Group I Thaumarchaeota assembled from metagenomes.

Environ Microbiol.

Luo, E., Aylward, F.O., Mende, D.R., and DeLong, E.F. (2017) Bacteriophage Distributions and

Temporal Variability in the Ocean's Interior. MBio 8: 1-13.

Mahmoudabadi, G. and Phillips, R. (2018) A comprehensive and quantitative exploration of thousands of viral genomes. Elife 7: e31955.

Maki, K., Kim, C., Yoshimizu, C., Tayasu, I., Miyajima, T., and Nagata, T. (2010) Autochthonous origin of semi-labile dissolved organic carbon in a large monomictic lake (Lake Biwa): Carbon stable isotopic evidence. Limnology 11: 143-153.

Martinez-Hernandez, F., Fornas, O., Lluesma Gomez, M., Bolduc, B., de la Cruz Peña, M.J., Martínez, J.M., et al. (2017) Single-virus genomics reveals hidden cosmopolitan and abundant viruses. Nat Commun 8: 15892.

Mehrshad, M., Salcher, M.M., Okazaki, Y., Nakano, S., Šimek, K., Andrei, A.-S., and Ghai, R. (2018) Hidden in plain sight—-highly abundant and diverse planktonic freshwater Chloroflexi. Microbiome 6: 176.

Mihara, T., Nishimura, Y., Shimizu, Y., Nishiyama, H., Yoshikawa, G., Uehara, H., et al. (2016) Linking Virus Genomes with Host Taxonomy. Viruses 8: 66.

Mizuno, C.M., Ghai, R., and Rodriguez-Valera, F. (2014) Evidence for metaviromic islands in marine phages. Front Microbiol 5: 1-10.

Mizuno, C.M., Ghai, R., Saghaï, A., López-García, P., and Rodriguez-Valera, F. (2016) Genomes of Abundant and Widespread Viruses from the Deep Ocean. MBio 7: e00805-16.

Mizuno, C.M., Guyomar, C., Roux, S., Lavigne, R., Rodriguez-Valera, F., Sullivan, M.B., et al. (2019) Numerous cultivated and uncultivated viruses encode ribosomal proteins. Nat Commun 10: 752.

Mizuno, C.M., Rodriguez-Valera, F., Garcia-Heredia, I., Martin-Cuadrado, A.B., and Ghai, R. (2013a) Reconstruction of novel cyanobacterial siphovirus genomes from mediterranean metagenomic fosmids. Appl Environ Microbiol 79: 688-695.

Mizuno, C.M., Rodriguez-Valera, F., Kimes, N.E., and Ghai, R. (2013b) Expanding the Marine Virosphere Using Metagenomics. PLoS Genet 9: e1003987.

Moon, K., Kang, I., Kim, S., Kim, S.-J., and Cho, J.-C. (2017) Genome characteristics and environmental distribution of the first phage that infects the LD28 clade, a freshwater methylotrophic bacterial group. Environ Microbiol 19: 4714-4727.

Moon, K., Kang, I., Kim, S., Kim, S., and Cho, J. (2018) Genomic and ecological study of two distinctive freshwater bacteriophages infecting a Comamonadaceae bacterium. Sci Rep 8: 7989.

Murase, J. and Sugimoto, A. (2005) Inhibitory effect of light on methane oxidation in the pelagic water column of a mesotrophic lake (Lake Biwa, Japan). Limnol Oceanogr 50: 1339-1343. 
Neuenschwander, S.M., Ghai, R., Pernthaler, J., and Salcher, M.M. (2018) Microdiversification in genome-streamlined ubiquitous freshwater Actinobacteria. ISME J 12: 185-198.

Newton, R.J., Jones, S.E., Eiler, A., McMahon, K.D., and Bertilsson, S. (2011) A guide to the natural history of freshwater lake bacteria. Microbiol Mol Biol Rev 75: 14-49.

Nishimura, Y., Watai, H., Honda, T., Mihara, T., Omae, K., Roux, S., et al. (2017a) Environmental Viral Genomes Shed New Light on Virus-Host Interactions in the Ocean. mSphere 2: e00359-16.

Nishimura, Y., Yoshida, T., Kuronishi, M., Uehara, H., Ogata, H., and Goto, S. (2017b) ViPTree: the viral proteomic tree server. Bioinformatics 33: 2379-2380.

Nurk, S., Meleshko, D., Korobeynikov, A., and Pevzner, P.A. (2017) metaSPAdes: a new versatile metagenomic assembler. Genome Res 27: 824-834.

Okazaki, Y., Fujinaga, S., Tanaka, A., Kohzu, A., Oyagi, H., and Nakano, S. (2017) Ubiquity and quantitative significance of bacterioplankton lineages inhabiting the oxygenated hypolimnion of deep freshwater lakes. ISME J 11: 2279-2293.

Okazaki, Y., Hodoki, Y., and Nakano, S. (2013) Seasonal dominance of CL500-11 bacterioplankton (phylum Chloroflexi ) in the oxygenated hypolimnion of Lake Biwa, Japan. FEMS Microbiol Ecol 83: 82-92.

Okazaki, Y. and Nakano, S.-I. (2016) Vertical partitioning of freshwater bacterioplankton community in a deep mesotrophic lake with a fully oxygenated hypolimnion (Lake Biwa, Japan). Environ Microbiol Rep 8: 780-788.

Okazaki, Y., Salcher, M.M., Callieri, C., and Nakano, S. (2018) The Broad Habitat Spectrum of the CL500-11 Lineage (Phylum Chloroflexi), a Dominant Bacterioplankton in Oxygenated Hypolimnia of Deep Freshwater Lakes. Front Microbiol 9:.

Paez-Espino, D., Eloe-Fadrosh, E.A., Pavlopoulos, G.A., Thomas, A.D., Huntemann, M., Mikhailova, N., et al. (2016) Uncovering Earth's virome. Nature 536: 425-430.

Parks, D.H., Chuvochina, M., Waite, D.W., Rinke, C., Skarshewski, A., Chaumeil, P.-A., and Hugenholtz, P. (2018) A standardized bacterial taxonomy based on genome phylogeny substantially revises the tree of life. Nat Biotechnol.

Paul, J.H. (2008) Prophages in marine bacteria: Dangerous molecular time bombs or the key to survival in the seas? ISME J 2: 579-589.

Paver, S.F., Muratore, D., Newton, R.J., and Coleman, M.L. (2018) Reevaluating the Salty Divide: Phylogenetic Specificity of Transitions between Marine and Freshwater Systems. mSystems 3: 347021 .

Posch, T., Köster, O., Salcher, M.M., and Pernthaler, J. (2012) Harmful filamentous cyanobacteria favoured by reduced water turnover with lake warming. Nat Clim Chang 2: 809-813.

Pradeep Ram, A., Nishimura, Y., Tomaru, Y., Nagasaki, K., and Nagata, T. (2010) Seasonal variation in viral-induced mortality of bacterioplankton in the water column of a large mesotrophic lake (Lake 
Biwa, Japan). Aquat Microb Ecol 58: 249-259.

Raymond, P.A., Hartmann, J., Lauerwald, R., Sobek, S., McDonald, C., Hoover, M., et al. (2013) Global carbon dioxide emissions from inland waters. Nature 503: 355-359.

Rodriguez-Brito, B., Li, L., Wegley, L., Furlan, M., Angly, F., Breitbart, M., et al. (2010) Viral and microbial community dynamics in four aquatic environments. ISME J 4: 739-751.

Rodriguez-Valera, F., Mizuno, C.M., and Ghai, R. (2014) Tales from a thousand and one phages. Bacteriophage 4: e28265.

Roux, S., Chan, L.-K., Egan, R., Malmstrom, R.R., McMahon, K.D., and Sullivan, M.B. (2017a) Ecogenomics of virophages and their giant virus hosts assessed through time series metagenomics. Nat Commun 8: 858 .

Roux, S., Emerson, J.B., Eloe-Fadrosh, E.A., and Sullivan, M.B. (2017b) Benchmarking viromics: an in silico evaluation of metagenome-enabled estimates of viral community composition and diversity. PeerJ 5: e3817.

Roux, S., Enault, F., Hurwitz, B.L., and Sullivan, M.B. (2015) VirSorter: mining viral signal from microbial genomic data. PeerJ 3: e985.

Salcher, M.M., Neuenschwander, S.M., Posch, T., and Pernthaler, J. (2015) The ecology of pelagic freshwater methylotrophs assessed by a high-resolution monitoring and isolation campaign. ISME J 9: $2442-2453$.

Salcher, M.M., Pernthaler, J., and Posch, T. (2011) Seasonal bloom dynamics and ecophysiology of the freshwater sister clade of SAR11 bacteria "that rule the waves" (LD12). ISME J 5: 1242-1252.

Segata, N., Börnigen, D., Morgan, X.C., and Huttenhower, C. (2013) PhyloPhlAn is a new method for improved phylogenetic and taxonomic placement of microbes. Nat Commun 4: 2304.

Shelton, A.N., Seth, E.C., Mok, K.C., Han, A.W., Jackson, S.N., Haft, D.R., and Taga, M.E. (2019) Uneven distribution of cobamide biosynthesis and dependence in bacteria predicted by comparative genomics. ISME J 13: 789-804.

Shen, W., Le, S., Li, Y., and Hu, F. (2016) SeqKit: A cross-platform and ultrafast toolkit for FASTA/Q file manipulation. PLoS One 11: 1-10.

Silva, B.S. de O., Coutinho, F.H., Gregoracci, G.B., Leomil, L., de Oliveira, L.S., Fróes, A., et al. (2017) Virioplankton Assemblage Structure in the Lower River and Ocean Continuum of the Amazon. mShere 2: 1-17.

Skvortsov, T., De Leeuwe, C., Quinn, J.P., McGrath, J.W., Allen, C.C.R., McElarney, Y., et al. (2016) Metagenomic characterisation of the viral community of lough neagh, the largest freshwater lake in Ireland. PLoS One 11: e0150361.

Small, G.E., Bullerjahn, G.S., Sterner, R.W., Beall, B.F.N., Brovold, S., Finlay, J.C., et al. (2013) Rates and controls of nitrification in a large oligotrophic lake. Limnol Oceanogr 58: 276-286.

Sullivan, M.B., Coleman, M.L., Weigele, P., Rohwer, F., and Chisholm, S.W. (2005) Three 
Prochlorococcus Cyanophage Genomes: Signature Features and Ecological Interpretations. PLoS Biol 3: e144.

Summer, E.J., Gill, J.J., Upton, C., Gonzalez, C.F., and Young, R. (2007) Role of phages in the pathogenesis of Burkholderia, or "Where are the toxin genes in Burkholderia phages?" Curr Opin Microbiol 10: 410-417.

Thingstad, T.F. (2000) Elements of a theory for the mechanisms controlling abundance, diversity, and biogeochemical role of lytic bacterial viruses in aquatic systems. Limnol Oceanogr 45: 1320-1328.

Thottathil, S.D., Hayakawa, K., Hodoki, Y., Yoshimizu, C., Kobayashi, Y., and Nakano, S. (2013)

Biogeochemical control on fluorescent dissolved organic matter dynamics in a large freshwater lake (Lake Biwa, Japan). Limnol Oceanogr 58: 2262-2278.

Touchon, M., Moura de Sousa, J.A., and Rocha, E.P. (2017) Embracing the enemy: the diversification of microbial gene repertoires by phage-mediated horizontal gene transfer. Curr Opin Microbiol 38: $66-73$.

Tranvik, L.J., Downing, J.A., Cotner, J.B., Loiselle, S.A., Striegl, R.G., Ballatore, T.J., et al. (2009) Lakes and reservoirs as regulators of carbon cycling and climate. Limnol Oceanogr 54: 2298-2314.

Warwick-Dugdale, J., Solonenko, N., Moore, K., Chittick, L., Gregory, A.C., Allen, M.J., et al. (2019) Long-read viral metagenomics captures abundant and microdiverse viral populations and their niche-defining genomic islands. PeerJ 7: e6800.

Weinbauer, M.G. (2004) Ecology of prokaryotic viruses. FEMS Microbiol Rev 28: 127-181.

Weinbauer, M.G., Brettar, I., and Höfle, M.G. (2003) Lysogeny and virus-induced mortality of bacterioplankton in surface, deep, and anoxic marine waters. Limnol Oceanogr 48: 1457-1465.

Wilhelm, S.W. and Suttle, C.A. (1999) Viruses and Nutrient Cycles in the Sea. Bioscience 49: 781-788.

Winter, C., Köstner, N., Kruspe, C.P., Urban, D., Muck, S., Reinthaler, T., and Herndl, G.J. (2018) Mixing alters the lytic activity of viruses in the dark ocean. Ecology 99: 700-713.

Wommack, K.E. and Colwell, R.R. (2000) Virioplankton: Viruses in Aquatic Ecosystems. Microbiol Mol Biol Rev 64: 69-114.

Woolway, R.I. and Merchant, C.J. (2019) Worldwide alteration of lake mixing regimes in response to climate change. Nat Geosci 12: 271-276.

Yoshida, T., Nishimura, Y., Watai, H., Haruki, N., Morimoto, D., Kaneko, H., et al. (2018) Locality and diel cycling of viral production revealed by a $24 \mathrm{~h}$ time course cross-omics analysis in a coastal region of Japan. ISME J 12: 1287-1295.

Yuan, Y. and Gao, M. (2017) Jumbo Bacteriophages: An Overview. Front Microbiol 8: 1-9.

Zaremba-Niedzwiedzka, K., Viklund, J., Zhao, W., Ast, J., Sczyrba, A., Woyke, T., et al. (2013) Singlecell genomics reveal low recombination frequencies in freshwater bacteria of the SAR11 clade.

Genome Biol 14: R130.

Zatopek, K.M., Gardner, A.F., and Kelman, Z. (2018) Archaeal DNA replication and repair: new genetic, 
bioRxiv preprint doi: https://doi.org/10.1101/655167; this version posted October 1, 2019. The copyright holder for this preprint (which was not certified by peer review) is the author/funder, who has granted bioRxiv a license to display the preprint in perpetuity. It is made available under aCC-BY-NC 4.0 International license.

biophysical and molecular tools for discovering and characterizing enzymes, pathways and mechanisms. FEMS Microbiol Rev 42: 477-488. 


\section{Figure legends}
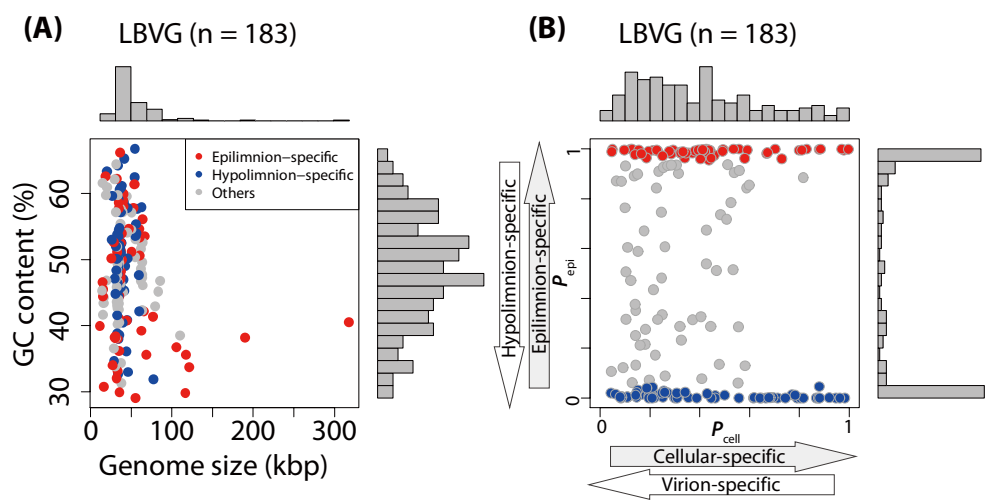

(C) $\operatorname{LBVC}(\mathrm{n}=4158)$
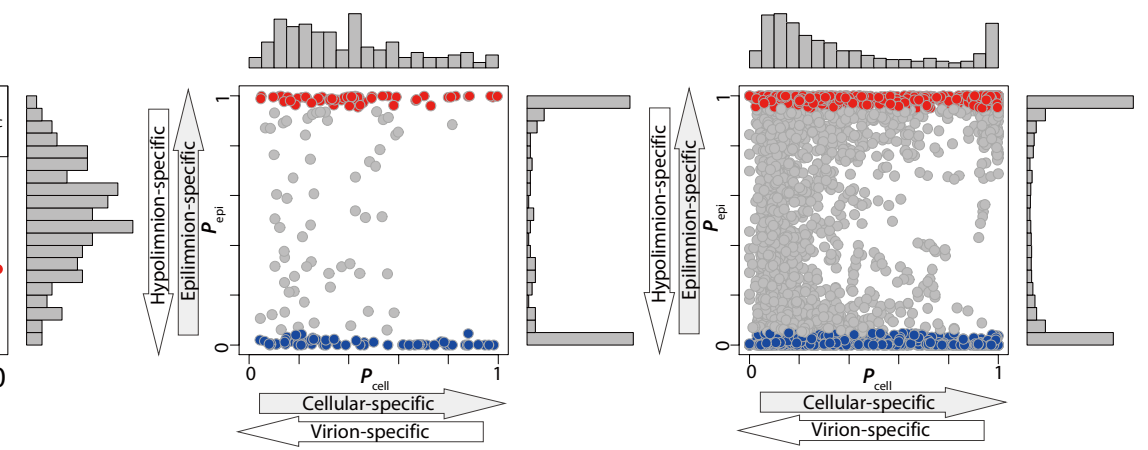

\section{Figure 1.}

Profiles of assembled viral genomes and contigs. (A) Distribution of genome size and GC content (\%) of Lake Biwa Viral Genomes (LBVGs). Habitat preferences of (B) LBVGs and (C) Lake Biwa Viral Contigs (LBVCs). The vertical and horizontal axes indicate the average $P_{\text {epi }}$ and $P_{\text {cell }}$ for each LBVG, respectively. Viruses with average $P_{\text {epi }}>95 \%$ and $<5 \%$ were designated as epilimnion- and hypolimnion-specific viruses and are indicated with red and blue points, respectively. 


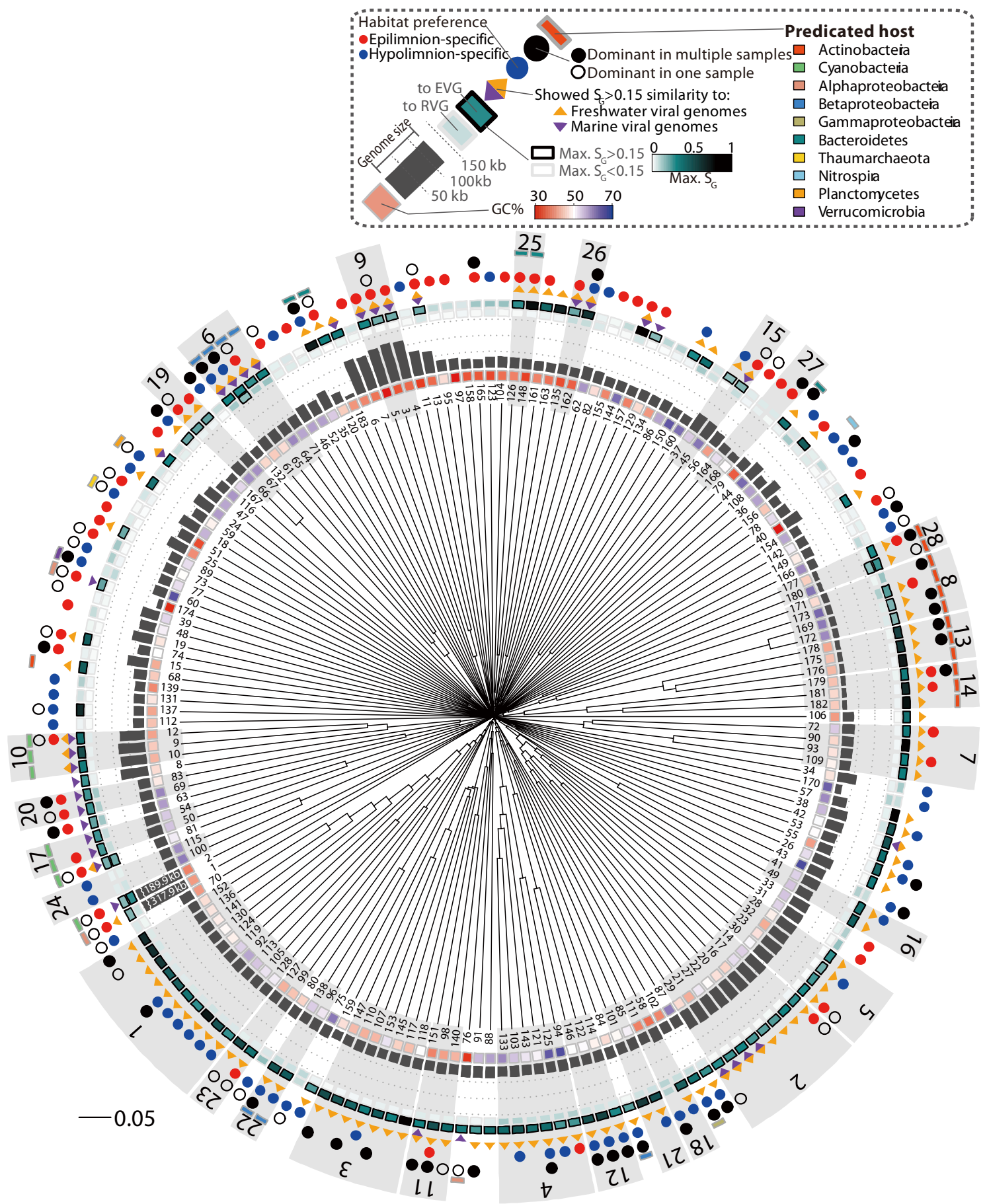

Figure 2.

Proteomic tree of 183 LBVGs with summarized analytical results. The gray shaded boxes indicate individual gOTUs with corresponding gOTU numbers. Annotation of epilimnion- and hypolimnionspecific viruses corresponds with the definition in Figure 1. "Dominant" viruses shown by the black and white circles indicate "ranked among the 10 most abundant viruses," as described in Figure 4. 


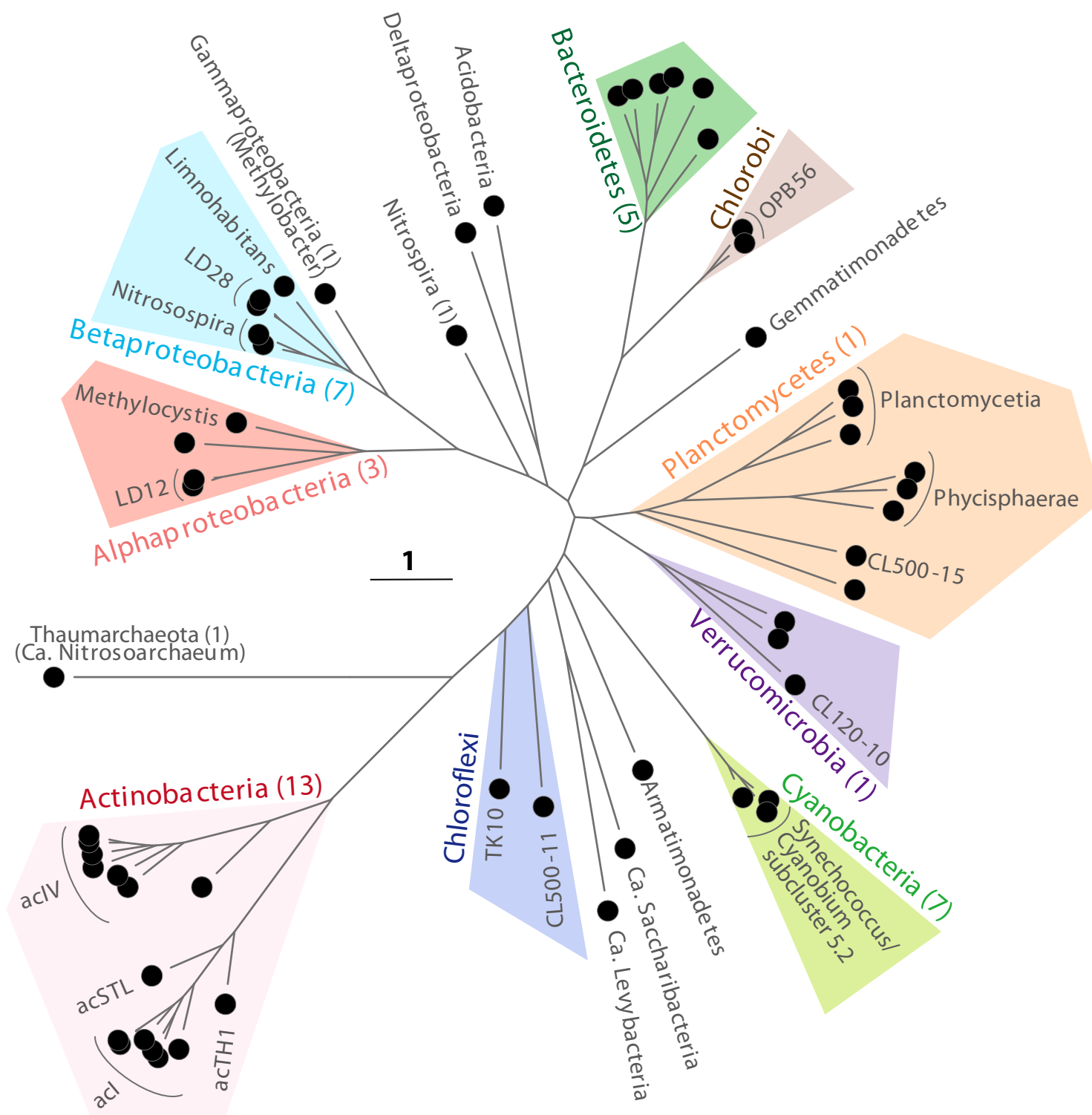

\section{Figure 3.}

A genome-resolved phylogenetic tree of Lake Biwa metagenome-assembled genomes (LBMAGs) based on conserved single-copy genes selected using PhyloPhlAn software. Members of the same phylum (or Proteobacteria class) were grouped by the same color shade. Numbers in parentheses indicate the number of LBVGs predicted to infect each taxonomic group. Note that Chloroflexi did not form a monophyletic clade here but did in a tree that included reference genomes (Fig. S3). 


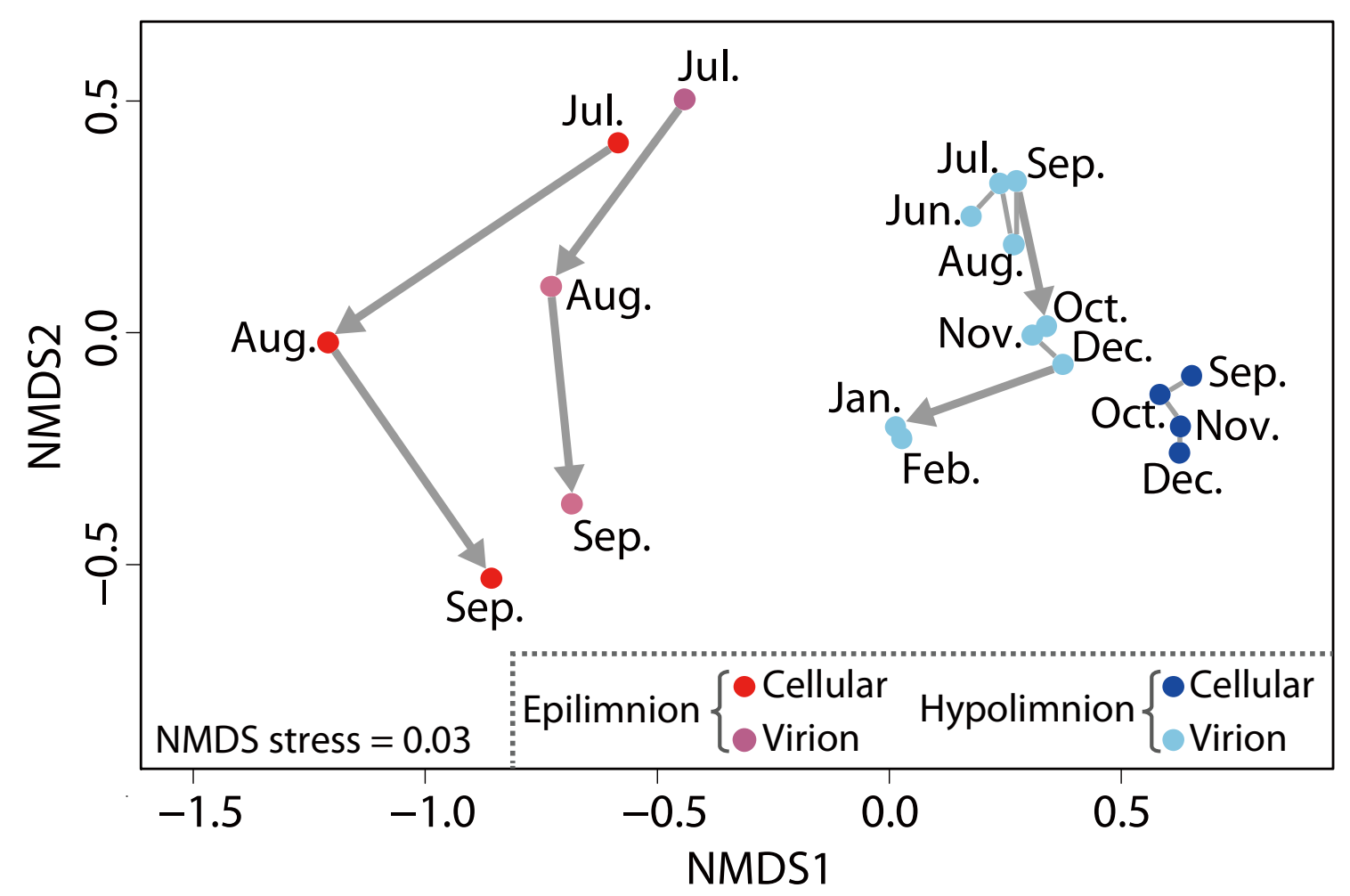

Figure 4.

Non-metric multidimensional scaling (NMDS) analysis showing dissimilarity of the viral community between samples. The distance between samples was calculated as Bray-Curtis dissimilarity based on the composition of the 183 LBVGs. Gray lines connect samples of consecutive months in the same sample fraction, where bold arrows indicate a large community shift with the Bray-Curtis dissimilarity of $>0.5$. 


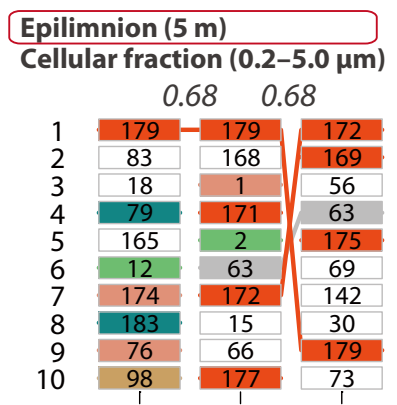

Jul. Aug. Sep.

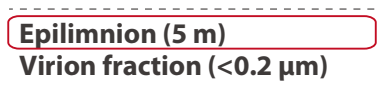

$0.54 \quad 0.60$

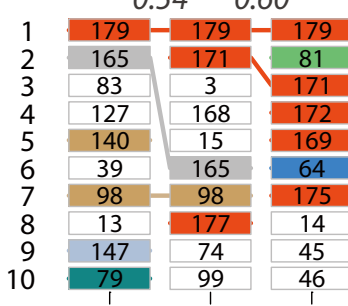

Jul. Aug. Sep.
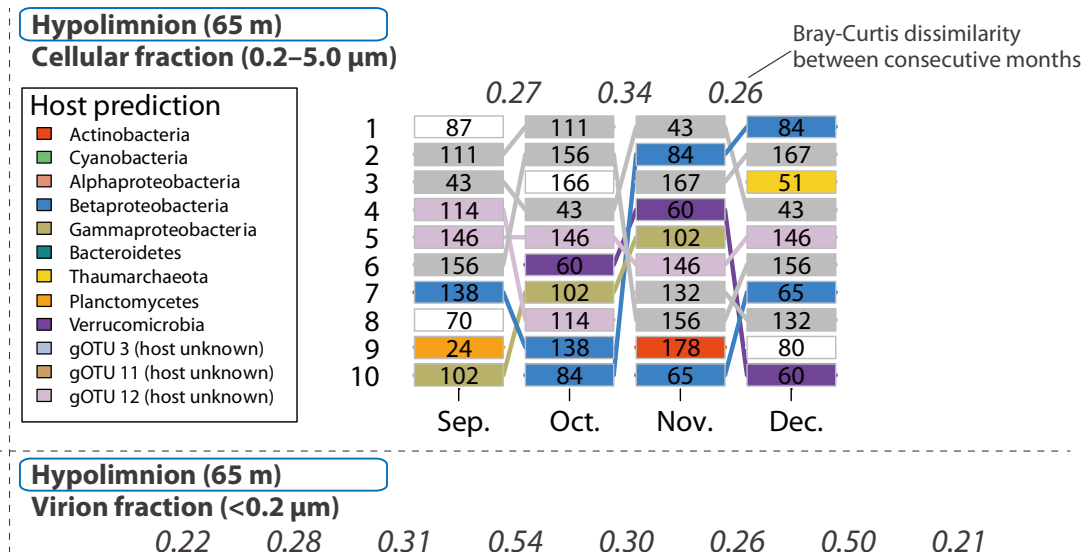

0.27

0.34

0.26
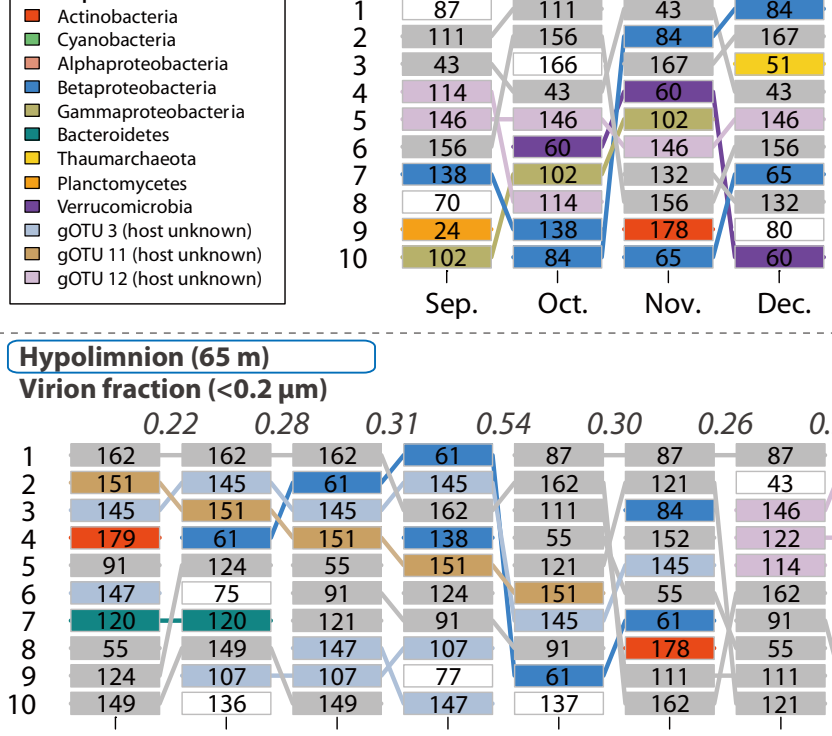

0.30

0.26

$0.50 \quad 0.21$

\begin{tabular}{|c|c|c|}
\hline 87 & 87 & 87 \\
\hline 162 & 121 & 43 \\
\hline 111 & 84 & 146 \\
\hline 55 & 152 & 122 \\
\hline 121 & 145 & 114 \\
\hline 151 & 55 & 162 \\
\hline 145 & 61 & 91 \\
\hline 91 & 178 & 55 \\
\hline 61 & 111 & 111 \\
\hline 137 & 162 & 121 \\
\hline 1 & & 1 \\
\hline & & 1 \\
\hline & & 1 \\
\hline
\end{tabular}

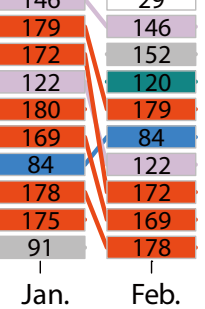

\section{Figure 5.}

Succession of the 10 most abundant viral genomes in each sample fraction. The number in each box corresponds to the number of LBVGs. The color of each box indicates the phylum of the predicted host. The abundant gOTUs (gOTU_3, gOTU_11, and gOTU_12) are also shaded, although their hosts remain unknown. Otherwise, members that were dominant over multiple months are in gray boxes and those that were dominant only within one month are in white boxes. Italicized numbers at the top of each panel indicate the extent of the community composition shift in consecutive months, based on the Bray-Curtis dissimilarity of the whole community. Quantitative data for this figure are available in Figure S4. 


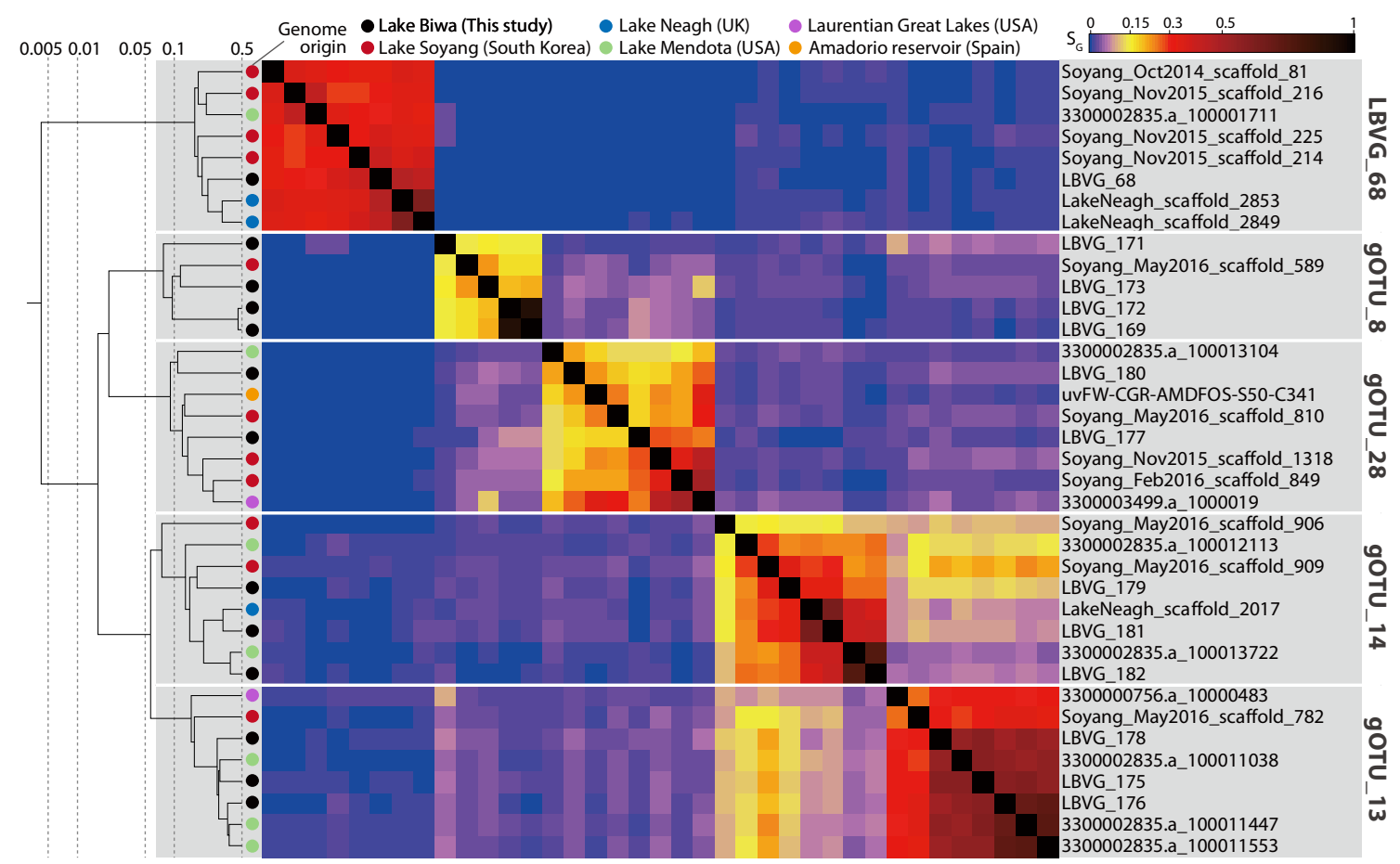

\section{Figure 6.}

Proteomic tree and $S_{\mathrm{G}}$-based pairwise distance matrix among five actinoviral groups identified in the present study and their close relatives in the Environmental Viral Genome (EVG) database. Alignments between individual genomes can be found in Supplementary Alignment S1. 